\title{
El Síntoma Psicoanalítico: Clínica y Cultura ${ }^{1}$
}

\section{The Psychoanalytic Symptom: Clinic and Culture}

\author{
Roberto Aceituno M. $^{2}$
}

\section{Resumen}

Se discute el problema de la historicidad de la clínica psicoanalítica, a la luz de su relación con el saber psiquiátrico y con las exigencias de su ubicación en la cultura. Tomando como referencia un análisis histórico-conceptual, se revisa la teoría freudiana para abordar críticamente el problema de la actualidad de la clínica y sus impases culturales. El análisis se centra específicamente en los trastornos limítrofes de la personalidad, en la cientificidad del psicoanálisis y en las consecuencias de una lectura contemporánea de la praxis freudiana.

Palabras claves: Discurso psiquiátrico, discurso psicoanalítico, subjetividad, cultura, época contemporánea.

\section{Abstract}

The article discusses the discoursive historicity of the psychiatric and psychoanalytic disciplines from two standpoints: the first, refers to the history of psychiatric and psychoanalytic discours; the second, refers to the "present" of psychiatric and psychoanalytic kwnowledge, in its relation to the problem analyzed before. The place of "borderlines" is analyzed specifically, considered as an expresion of both a disciplinary constancy and contemporary subjectivity in its social-cultural dimension. .

Key words: Psychiatric discours, psychoanalytical discours, subjectivity, culture, contemporary times.

\footnotetext{
1 Este trabajo se basa en la Tesis de Doctorado (2000) "Elements historiques du discours psychiatrique et psychanalytique.Ver l historicité de leurs limites" Laboratorio de Psicopatología Fundamental y Psicoanálisis Universidad Denis Diderot Paris VII Aceituno R. 2 Psicólogo, Psicoanalísta Académico Dpto de Psicología Universidad de Chile, dptopsic@uchile.cl
} 


\section{El Problema: Clínica Psicoanalítica y Lazo Social}

La praxis freudiana supone una interrogación crítica sobre el sujeto en la cultura. Ya sea que se plantee en una perspectiva metapsicológica, antropológica o nosológica, la clínica psicoanalítica implica una aproximación a lo que en cada sujeto, y en el contexto socio-cultural donde éste existe, se produce como discurso. Este estatuto, a la vez singular y social de la práctica del análisis, ha sido retomado por diversos autores postfreudianos, y alcanza una expresión específica en el privilegio otorgado por Jacques Lacan a la función de la palabra en la estructura inconsciente, así como al carácter discursivo de la relación al Otro -relación definida como búsqueda de un saber que encuentra ahí sus propios límites. Decir que la teoría psicoanalítica es una teoría critica sobre el sujeto en su alteridad fundamental, acarrea consecuencias para la manera como puede ser considerado el trabajo clínico, que es su soporte específico.

Las reflexiones que siguen, intentan desarrollar algunas hipótesis teóricas relativas al lugar de la clínica psicoanalítica en la ciudad, lugar que supone la historicidad de sus apuestas, a la par que la historicidad del sujeto (o del síntoma) comprometido en dicha experiencia.

Específicamente, se abordarán a continuación los siguientes aspectos del problema enunciado:

1. Historicidad de la clínica, historicidad del psicoanálisis, historicidad del sujeto.

2. Psicoanálisis versus Psiquiatría?: límites de la psiquiatría, fronteras del psicoanálisis.

3. Un ejemplo paradigmático: los "trastornos limítrofes de la personalidad". Hipótesis para una crítica actual.
4. Desafíos para el psicoanálisis contemporáneo: clínica y escritura.

\section{Antecedentes Teóricos e Históricos}

La praxis psicoanalítica, ya sea entendida en su dimensión teórica o como una práctica clínica particular (oposición, por lo demás, relativa), surge en un contexto cultural específico. La relación a la ciencia, invocada por Freud a lo largo de toda su obra, define parte importante de ese contexto, en la medida que el discurso científico es, paradójicamente tal vez, tanto el ideal al cual intenta aproximarse, como el reverso de la racionalidad en la que Freud se situó para definir al sujeto, como sujeto del inconsciente. Dicha dependencia/diferencia de la teoría freudiana con respecto al ideal científico -y a la práctica médica que es, para este caso, su representante particular- es visible en la relación que Freud establece con la histeria: ésta representa -y encarna- la búsqueda de un saber que nombre sus síntomas (particularmente corporales), pero a costa de un fracaso; fracaso que compromete al saber mismo. La resistencia del síntoma a dejarse llevar por un saber centrado en la racionalidad médica de la época de nacimiento del psicoanálisis, es paradójicamente la condición de posibilidad del discurso analítico mismo. La sexualidad de la histeria representa entonces ese territorio enigmático que produce síntomas, porque la sexualidad es sintomática en si misma. La teoría freudiana es heredera de esa búsqueda de saber (en ese sentido, podríamos decir que el psicoanálisis le debe a la histeria su carta de nacimiento), pero a costa de encontrarse con lo que el propio saber "clásico" no podía nombrar sino como déficit, como sombra o como vicio. Así, entre una teoría sobre la relación del sujeto al lenguaje, y una teoria sobre lo que hace de límite a esa misma relación (la dimensión 
pulsional de la experiencia subjetiva), circula la producción del concepto del inconsciente a la luz de las condiciones socio-históricas que lo hicieron formulable "científicamente".

En este marco, podría pensarse que la teoría freudiana sobre el sujeto del inconsciente es completamente ajena a los desarrollos que precedieron a la invención del psicoanálisis, los cuales, como se sabe, estuvieron marcados por la entrada del vasto campo de las neurosis al "templo de la ciencia" en la medicina decimonónica (Trillat, 1986). Tal diferencia, incluso rivalidad, entre ambos dominios (medicina/psicoanálisis), es perceptible en la relación que Freud estableció con el discurso psiquiátrico de su época, del cual puede decirse que operó como uno de sus adversarios teórico-prácticos (Certeau, 1986; Aceituno, 1999). Es posible rastrear en los textos freudianos este intento por sostener su especificidad discursiva al margen de los desarrollos nosológicos y nosográficos que le fueron contemporáneos. Más que una teoría del síntoma, entendido como una relación médica a los "signos" de la enfermedad, el discurso de Freud supuso una aproximación a lo que hace síntoma en el sujeto mismo, en su conflictiva entrada al mundo de la sexualidad y de la diferencia. La teoría freudiana hizo del síntoma un asunto subjetivo, desplazando la relación puramente epistémica al cuerpo o a la conciencia hacia un territorio de otro orden, donde ambos cuerpo y conciencia- mostraban sus límites naturales para ofrecerse como territorios de lenguaje y de pulsión (Birman1999).

Sin embargo, es preciso reconocer que tal diferencia, o tal rivalidad, hay que leerla teniendo como contrapartida una hipótesis inversa: según ésta, el psicoanálisis habría surgido a partir de las condiciones establecidas durante el recorrido disciplinario que parte de Pinel y que se prolonga en la psiquiatría de fines del siglo XIX (Swain y Gauchet 1997). Desde esta perspectiva, la teoría y la práctica freudiana no sería sino la prolongación de una vieja historia: aquella que separó al alienado de sus ataduras ancestrales-las que lo ligaban al pensamiento mágico y al poder de una época que lo hacía extranjero absoluto de la Razón- para definir en cambio la alienación como constituyente de la racionalidad misma. Así, de ser una exiliada de las ciudades del mundo, de ser una viajante extraviada en su propia insensatez (Foucault 1996), la locura -luego la enfermedad mental, finalmente la neurosis y el hombre común- pasó a definirse entonces como un "revelador antropológico" (Gauchet 1984) que decía más del hombre que la propia razón que lo miraba desde lejos. Desde este punto de vista, la invención del psicoanálisis sería heredera de este "nuevo régimen de la alteridad" (Gauchet y Swain1984): desde entonces, la alienación no sería pura distancia, pura diferencia o puro exilio subjetivo, sino que sería parte constitutiva de la razón misma.

Las dos versiones que hemos introducido hasta aquí, con respecto a la "novedad" de la invención freudiana, dicen, en su tensión misma, algo de la verdad del lugar del psicoanálisis en la cultura, y es en este sentido que el psicoanálisis opera él mismo como un "síntoma", como un conflicto a ser descifrado en su textualidad, es decir según como es leído. Como veremos más adelante, estas lecturas del psicoanálisis, en los impases de la clínica actual, pueden subrayar uno u otro polo de las dos versiones señaladas precedentemente.

Pero antes de entrar en ese debate, es decir, el lugar del psicoanálisis en la cultura hoy en día, y antes de retomar el problema de su eventual matrimonio o de su eventual rivalidad con el discurso psiquiátrico, es necesario tramitar la contradicción señalada a partir de una tercera posibilidad crítica; precisamente aquella que hace de la tensión del discurso freudiano a la historia (a su historia) una vía para pensar, a la vez, su especi- 
ficidad y su continuidad con respecto a la deriva psiquiátrica del siglo antepasado.

\subsection{La historicidad de la clínica a la luz de la historicidad del psicoanálisis}

Un camino para entender de otro modo la contradicción antes señalada, hace alusión a la manera como el discurso analítico inaugurado por Freud, opera en la tensión entre lo que aporta como "novedad" crítica y las condiciones históricas que lo hicieron posible. Dicha tensión se expresa en la manera como Freud introduce una perspectiva histórica para iluminar algo de los impases de su actualidad, tal como en otro registro la dinámica misma del síntoma neurótico requiere desde esta perspectiva freudiana un tiempo precedente para ejercer su eficacia retroactiva. En este sentido, la historicidad del texto freudiano, análogo en cierto modo a la historicidad del síntoma (del sujeto), representa una via para superar la contradicción simple de una "novedad" o de una "continuidad" enunciativa en el discurso analítico mismo. Como veremos más adelante, es este mismo problema el que se plantea cuando se discute la "novedad" de las patologías psíquicas de hoy (Narot, F., 1990), en tanto éstas pueden entenderse como diciendo algo de la manera como el sujeto -correlativamente a sus "síntomas"- expresa las condiciones siempre "actuales" de su lugar en la cultura, pero donde dicha "actualidad" recapitula un tiempo precedente.

En este sentido, y más específicamente, podemos decir que el discurso psicoanalítico "hereda" de la cultura decimonónica uno de sus problemas fundamentales, esto es la búsqueda de una "identidad" remecida por el relativo derrumbe de sus referencias clásicas (la religión, por ejemplo) en lo que se ha denominado, con Weber, "el desencantamiento del mundo" propio a la cultura burguesa (Weber 1964). Gran parte del desarrollo de la psiquiatría del siglo XIX, evidencia esa búsqueda a través de los dispositivos disciplinario-normativos, ya sea en la construcción de figuras nosológicas o nosográficas que expresaban un nuevo estatuto de la alteridad, del conflicto y de la extrañeza (por ejemplo, a través de las figuras "limítrofes" de salud y locura, de normalidad y de crimen), como también en el propio lugar de las disciplinas (aquí la psiquiatría) en lo que se ha denominado, con Foucault y otros, la "sociedad de la normalización" (Foucault1997; Castel 1976). En este contexto, la continuidad que hemos mencionado entre la psiquiatría decimonónica y el discurso psicoanalítico freudiano releva de una continuidad de problemas culturales, para lo cual el inventor del psicoanálisis debió situarse en el centro de dicha problemática identitaria, pero para tramitarla de manera diversa.

Un ejemplo de esta tensión por la cual Freud es tributario de una "vasta cultura clásica", pero introduciendo ahí mismo una subversión de sus puntos de apoyo doctrinarios, se expresa en la relación de Freud a las grandes producciones culturales (arte, literatura, etc.) y, de modo más específico, en su relativo parentesco a los problemas y apuestas del romanticismo decimonónico. Tal como ha sido señalado por Michel Foucault (1997), la medicina del siglo XIX es tributaria de la emergencia del individuo como objeto de conocimiento y de producción literaria, individualidad que se define sin embargo en estrecha dependencia a la evidencia de la muerte como límite y condición de posibilidad de esa experiencia "trágica". Freud se hace parte de esta "nueva conciencia de la finitud" (Foucault 1996), pero para tramitarla más allá de las referencias al cuerpo y su anatomía, a la muerte como destino y a la conciencia como patrón de medida, hasta entonces, de lo "psíquico por excelencia".

Podemos decir entonces que no es casual que Freud se vuelva hacia un tiempo prece- 
dente (la cultura romántica, o más lejanamente las producciones artísticas de un Leonardo o de un Miguel Angel) pero para instalar desde ahí una reflexión sobre lo que dicha producción muestra de la dependencia del sujeto a un discurso que lo condiciona en su "alteridad fundamental". De ahí, finalmente, que Freud deba en otro plano "volverse" hacia la religión de sus ancestros (Freud 1986) -con toda la conflictiva propia a Freud mismo- para establecer a través de los mitos originarios de la cultura los puntos de apoyo de su propio presente. Presente que, como es reconocible históricamente, estaba marcado por el destino trágico de esa misma cultura de la que formaba parte, aun con su resistencia a dejarse llevar por una transmisión ciega de una religiosidad que cuestionó recurrentemente.

En resumen, podemos decir hasta aquí que el discurso freudiano es un síntoma. En tanto hecho de cultura, y organizado a partir de una textualidad a veces literaria y a veces estrictamente científica, el síntoma psicoanalítico expresa un conflicto que es propio al hombre de su época, que busca salvar su identidad a costa de la orfandad de sus referencias. El concepto de inconsciente, como los mecanismos específicos que lo encarnan subjetivamente (por ejemplo, a través de la represión como pilar de su doctrina, o a través de la sexualidad infantil como otro de sus principios fundadores), es un efecto y causa a la vez de este nuevo régimen de la alteridad/ identidad en la cultura occidental.

\section{2. ¿Psiquiatría versus psicoanálisis?}

Si la relación del discurso psicoanalítico a las bases histórico-culturales que son sus condiciones de aparición muestra esta tensión entre su eventual ruptura y su posible continuidad enunciativa, es en su relación al discurso psiquiátrico donde dicha tensión se puede expresar más específicamente.
Ahora bien, no es ciertamente en el plano de la identidad disciplinaria donde se puede hallar la relación conflictiva de la clínica freudiana respecto a los antecedentes que hemos descrito precedentemente. El propio Freud mostró a ese respecto una posición ambigua: por una parte, señalando que entre una (la psiquiatría) y otro (el psicoanálisis) no podía haber sino continuidad, basada en la naturaleza de sus "objetos" (Freud 1990a) y subrayando que "es el psiquiatra y no la psiquiatría quien se opone al psicoanálisis". Pero, por otra parte, Freud no dejó de plantear sus dudas más o menos irónicamente acerca de la cientificidad de la primera, la misma que no cesó de reclamar para la otra: "en el marco mismo de la medicina, la psiquiatría, ..., se ocupa de describir los desordenes psíquicos que observa y de reunirlos en cuadros clínicos, pero en sus buenos momentos, ¿se han preguntado los psiquiatras mismos si sus arreglos puramente descriptivos merecen el nombre de ciencia?" (Freud1990; Decourt 1996).

En otro plano, es evidente que las intervenciones (o incluso las rupturas) de Freud al interior del saber psiquiátrico no podían sino utilizar las categorías nosológicas de su época, aun cuando habilitaran ahí mismo modificaciones conceptuales de amplio alcance clínico (las psicosis, la separación de las neurosis, etc.). Ciertamente la clínica freudiana se sitúa en el campo psicopatológico de su épo$\mathrm{ca}$, aun cuando progresivamente ese esfuerzo "descriptivo" que le asignaba al rol del psiquiatra pudiera ser superado (o al menos complementado) con una teorización de alcance mucho mayor: sea en cuanto podía reclamar para la naciente "ciencia" un estatuto particular, basado en la especificidad de su objeto -el inconsciente-, sea porque el carácter puramente sintomatológico de las distribuciones nosográficas debía dar paso a una reflexión sobre los "mecanismos" de la formación de síntomas y alcanzar, por esta vía, 
una dimensión "antropológica" que desbordaría los limites psicopatológicos al interior de los cuales había fundado sus aproximaciones inaugurales (particularmente, como se sabe, a propósito de la clínica de la histeria). En este sentido, el trabajo freudiano tendió progresivamente a hacer uso de los enunciados -y de las prácticas- psicopatológicas de su época, pero para elaborar desde ahí una interrogación sobre el sujeto que desbordaría completamente las fronteras de su identidad disciplinaria (o profesional). Lo atestiguan: la elaboración de las apuestas metapsicológicas-que descansaban por lo demás en los límites y enigmas que le proponía la clínica-; la construcción de una teoría que ligaba afectos (pulsiones) y representaciones (lenguaje) para fundar una "estilistica de la existencia" (Birman 1999) y donde el sujeto sólo podía ubicarse en la relacion de ambos dominios, en la tensión que se planteaban mutuamente; en fin, para ir más lejos, en los alcances de su "interpretacion de la cultura". En todo ello, Freud operó una progresiva re-definición de sus apuestas a la vez clínicas y antropológicas, desplazando los dominios iniciales de la descripción -incluso de la etiología- hacia una interrogación sobre la manera como una teoría del síntoma o de la neurosis -o sobre el inconsciente mismo- debía incluir necesariamente al sujeto -aun en su excéntrica determinación- como momento necesario para establecer el valor a la vez conceptual, clínico y, en cierto modo político, de su doctrina. Más que una clínica del síntoma, el freudismo supuso una teoría sobre el sujeto. $\mathrm{O}$, dicho de otro modo, el sujeto se hizo síntoma.

Esta revalorización del sujeto marca ya un giro respecto a las aventuras de la clínica psiquiátrica. No porque en ella aquél estuviera ausente del todo, o que se hubiera rechazado completamente, sino porque de una manera más fundamental es el sujeto mismo el que aparece interrogado progresivamente en su división y donde el carácter psicopatológico debía entenderse a la par de un malestar propio a la cultura. Este paso del sintoma al sujeto (o de una versión restringida del síntoma hacia una problematización de lo que hay de sintomático en el sujeto mismo) adquiere sentido entonces para nosotros no solamente en la relación más o menos "diplomática" o más o menos crítica que pudo establecer con la clínica psiquiátrica, de la cual se hizo parte inevitablemente; también -y sobre todo- porque este movimiento se establece en los reiterados giros y reformulaciones al interior de su propio ejercicio teórico y clínico. Esto último es perceptible, por realizar sólo una lectura superficial, en los momentos claves de las inflexiones freudianas:

Problemas de causalidad : en la reformulación fantasmática de la hipótesis sobre el trauma psíquico (Freud 1974; Chiland 1990; Laplanche y Pontalis 1985)

Problemas técnicos -en el privilegio otorgado al análisis de la resistencia (Freud 1990c; Freud 1984) como función donde el carácter dinámico de la formación de síntomas -y su develamiento- debía considerar la tensión que el propio sujeto le planteaba a la produccion del "material"; es decir, donde el sujeto se hacía parte, mediante su afirmacion o su silencio, de los materiales que ofrecía como texto a descifrar.

Problemas metapsicológicos : en el paso de la tópica centrada en el privilegio otorgado, aun críticamente, a la conciencia para establecer el lugar y el funcionamiento de la vida psíquica, hacia una tópica donde los "atributos" de lo psíquico, o incluso su "realidad" , darían paso a una configuración de un modelo a la vez "trágico" (personajes, escenas) y de un funcionamiento en un 
"aparato" definido subjetivamente (Yo, Ello, Superyó).

- Dimensión "económica" del funcionamiento psíquico, en el paso de las doctrinas pulsionales: del primado del principio del placer a la teoria sobre la pulsion de muerte y la repeticion;

- $\quad$ en fin, en el retorno de la problemática de los orígenes, que la clínica la le había planteado "histéricamente", hacia la interrogación sobre el "origen" de la civilización o de la religión de sus antecesores -aquí donde la construcción del mito fantasmático de un comienzo, aquél que le había permitido en la singularidad de la cura relevar la construcción imaginaria y retroactiva de una "verdad" tomada como causa, se desplazaría hacia la trans-subjetividad de una historia cultural marcada por la producción sintomática (es decir, en la división misma del sujeto) de ese origen repetitivo.

En todo ello, Freud desborda los alcances puramente clínicos de sus aproximaciones teóricas para avanzar en una problematización del sujeto que no coincide con su estatuto de "objeto" de conocimiento ("científico") y que implica en cambio -desde ahí- una interrogación explícita o implícita sobre su dimensión antropológica. Si la base de la intervención freudiana fue la psiquiatría, su instalación cultural depende en gran parte del abandono de los estrechos límites de su identidad disciplinaria.

Proponemos entonces que es a pesar y no necesariamente debido a su ubicación clínica que el psicoanálisis se mostró en su valor de índice cultural. Pero también, es lo que queremos destacar, esta tensión ocurrió en su propia deriva teórica y clínica: no sólo a costa de la psiquiatría, sino también a costa de si mismo.

\section{Freud y sus Alrededores}

En un sentido más preciso, nos interesa ahora subrayar algunos aspectos de la diferencia-de estilo, de método-por la cual Freud toma distancia, ya desde sus primeras producciones teorico-clínicas, de sus antecedentes y de sus primeras alianzas de formación y de trabajo (Andersson 1997) Dichas diferencias operan de manera explícita en la relación que Freud estableció con su maestro Charcot (Porge 1984; Assoun 1990), así como con uno de sus contemporáneos, en el caso de Janet (1894).

Charcot fundaba su clínica en dos premisas fundamentales: por una parte, en el privilegio otorgado a la mirada en la determinación de los signos visibles de la enfermedad, para fundar una clínica donde en la amplitud de los fenómenos mórbidos pudiera reconocerse una unidad nosológica; donde el "caos" multiforme de las apariencias pudiera ser "ordenado" en función de una ley unificadora. En este sentido, Charcot se ha hacía parte de toda una tradición clínica: en particular, el acceso a lo real de la enfermedad para construir una tipología que le permitiera ubicar en el campo formal de las especies mórbidas. Charcot dirá entonces que su labor no es sino "fotográfica" (Charcot 1888; Didi-Huberman 1994). Así, Charcot incluía en un mismo gesto el rigor de las descripciones clínicas con este primado de lo visual que lo acercaba, en palabras de Freud, al trabajo de un "artista" (Assoun 1990). Pero este "arte" estaba destinado, en la pintura del "cuadro" clínico, a un trabajo de "ilustración", es decir se dirigía a un destinatario (el público de sus famosas presentaciones) ávidos de reconocer ahí el saber del maestro. Menos que interrogar la verdad ofrecida en el sufrimiento del enfermo, menos que elaborar desde ahí una teoría que permitiera avanzar en el "sentido" o en la "causa" de su destino o de su "funcionamiento", la la- 
bor de Charcot apuntaba más bien a elaborar ese cuadro razonado de distinciones nosológicas a las que se habían dedicado los primeros alienistas, pero mediante el devenir de una presencia: así, en la representación escénica (teatral) del diálogo del maestro con el enfermo (o con la enfermedad más bien), podía aparecer lo "nuevo" de la enfermedad ofrecida a la mirada, pero cuya función -en Charcot- no era otra cosa que integrarse (y producir) un ordenamiento que el "caos" de las apariencias ocultaba en su desorden: "No es una novela, la histeria tiene sus leyes" (Didi-Huberman 1994).

En paralelo a esta primacía de la imagen y de la mirada en la escena de Charcot, su clínica buscará las construcciones de tipos ideales, es decir, la delimitación de una esencia mórbida de la cual los síntomas y los fenómenos psicopatológicos serían su expresión contingente y, por cierto, deformada. En este sentido, el método anatomo-clínico de larga historia, aparecía reflejado en el nuevo espacio abierto por las enfermedades del alma. Por otra parte, el carácter psicológico (o más bien "moral") de las alteraciones, constituía mas bien el adjetivo secundario de una enfermedad en última instancia orgánica. De ahí que para Charcot la psicología, para los efectos de sus problemas, pertenecie$r a$ a la medicina y que no fuera "al menos en su mayor parte, sino la fisiología de las partes superiores o nobles del cerebro" (Gauchet y Swain1997).

Freud hereda entonces de Charcot -y de toda una tradición clínica- la necesidad de situarse frente a lo real del sufrimiento del enfermo, en el ofrecimiento de éste a un saber médico. Pero este real, más allá de presentarse como la expresión visible-o deducible- de las "imágenes de la enfermedad", operaba para Freud en función de una experiencia irreductible a un saber dado por descontado $y$, en este sentido, alimentaba su valor de "enigma" a resolver indefinidamente (Assoun
1990). Pero esta actitud que suponía, por ejemplo respecto a las "historias de casos", menos la ilustración de la teoría que la introducción en ésta de los limites de su cobertura explicativa, y permitiendo que avanzara a expensas de sus lagunas, no implicaba solamente una petición de principios generales, sino que se desarrollaba al interior de su propio movimiento discursivo. Así, lo real en cuestión no residía en aquello que la cientificidad buscada pudiera alcanzar asintóticamente, instalada en el orden de una tipología clínica, sino en aquello que insiste en la tensión de la teoría frente a su otro; es decir, en los limites impuestos por el caso a la teoría misma. Cuestión, por lo demás, que alimentará la dialéctica por la cual el desarrollo de la teoría, en Freud, se irá formando por lo que ella ya no comprende. Un real entonces que no opera como el límite último de una verdad inaccesible, administrada por la universalidad del orden (o de la Ley), sino como una insistencia que sólo la ficción teórica podrá utilizar y hacer enunciable (Assoun 1995). Un real que es parte, para decirlo mas radicalmente, de la intervención del sujeto (tanto Freud, en este caso, como sus interlocutores) en lo inconsciente que su "sufrimiento" hace emerger como síntoma o como palabra.

Lo real de la clínica se sitúa entonces, para Freud, en virtud de las "resistencias" que el caso le ofrece a su trabajo develador. Cuestión que acarreará alcances no solamente al interior de su práctica (aquí divorciada de la actitud del maestro Charcot), sino que impulsará una interrogación de más amplia cobertura: desde su desencanto frente a la hipótesis traumática entendida como acontecimiento en la realidad "historica" del paciente -para habilitar precisamente un concepto de realidad (fantasmática, ficcional) y de historia (en acción diferida) que las sitúa a ambas de manera problemática respecto a la causalidad que buscaba infatigablemente el saber medico-hasta que en sus últimos días 
la búsqueda imposible-y necesaria- del origen lo impulse a deconstruir el mito individual de un comienzo definitivo (del padre seductor de la histeria hasta el padre primordial, devenido asunto de escritura en el deseo freudiano de ir mas allá de una ley anónima y sin tiempo).

De manera que es el movimiento de negación permanente de las hipótesis construidas a lo largo de su obra, a la par de la afirmación recurrente de una posición de autoridad (en el sentido mas de autor que de autoritarismo), se constituye en Freud como parte integrante de su lógica misma. Ahí donde la clínica de su época no podía sino ejercer el rol clásico de la ilustración o bien encaminarse hacia la búsqueda de una eficacia -comandada por el progresivo lugar de la psicoterapia-, Freud introdujo la posición del sujeto (tanto en el clínico como en paciente) aun (y debido a ) su determinación como sujeto de deseo.

Sin embargo, este movimiento no implica, para Freud, un mero subjetivismo. Si hay interrogación sobre el sujeto, es en tanto éste se muestra en la determinación que recibe de una "realidad" que no puede ser identificada a la realidad psiquica (al menos a la conciencia que constituía por entonces el patrón de medida de lo psíquico en general) ni tampoco a una realidad en ultima instancia "material" (o corporal) (Freud 1990d). Pero tampoco se trata, en Freud, de una perspectiva que apunte a señalar en el "individuo" la sede única de su verdad como sujeto. Se trata en cambio de una realidad que necesita, al menos, del devenir de una historia para ejercer sus "efectos" sintomáticos, es decir subjetivos, en la transindividualidad de sus determinaciones. Esto vendrá a ser sancionado teóricamente por la construcción de la segunda tópica, por el concepto dinámico de represión (vs. de inconsciente) -o su equivalente técnico en la resistencia-, por el progresivo desarrollo de las hipótesis del fan- tasma y, en definitiva, por la articulación de una "estructura" respecto a la configuración trágica del Edipo.

Pero, por otra parte, y volviendo a nuestra discusión sobre la relación de Freud a la clínica de su época inicial (en particular respecto a Charcot), esta reivindicación del sujeto en virtud de lo real de su sufrimiento o de sus síntomas, opera en Freud mediante su propia participación en ese límite -y posibilidad- "real" que le ofrece esa alteridad y que introduce, via "caso", un tope activo a la seria cientificidad de su abordaje clínico. Dicha participación opera, para lo que nos interesa, en la implicación del autor (Freud) frente a la incomodidad de sus certezas, devenidas el motor de su reformulación permanente. Implicación que ocurre, en Freud, mediante el desasosiego frente a una obra siempre "inconclusa" y que llevar a ejercer en su propia escritura ese efecto retroactivo que reclamaba para la eficacia sintomática.

Freud hereda entonces de Charcot y de su "vasta cultura clásica", más un espíritu (científico) que un método, más una actitud que una forma de conocimiento. Es en este sentido que se inscribe la relación de Freud al caso clínico, devenido para él un asunto mas de narración que de explicación o de descripción; una narratividad sometida a las exigencias de una novela cuya función podía alimentar el rodeo fantasmático de un real que se escondía y se mostraba en él.

Desde este punto de vista, teoría y clínica, lejos de funcionar como dos dominios extraños el uno al otro (donde la segunda podía ilustrar a la primera, o donde ésta podía ofrecer el marco explicativo de aquella), participan, en Freud de un mismo proceso escritural: ambas se sostienen en la narratividad fantasmática de una ficción que rodea las "cosas últimas" haciendo intervenir al autor en sus propios límites y, con ello, en su posibilidad de sentido. Pero una narratividad que 
supone el alejamiento de una mera descripción impresionista del "cuadro" y que implica un movimiento temporal que, en el transcurso de una vida (o de una cura) pueda a posteriori revelar el secreto de su origen.

Si la hipótesis del fantasma introduce en la naturaleza misma del síntoma el estatuto subjetivo de su ficción y de su deseo; si la necesidad de un tiempo primero, aparentemente destinado a fijar los orígenes de la Ley y de la transmisión (Totem y Tabú) una vez que lo acontecido de las escenas primordiales (El Hombre de los lobos) implicara una participación activa del sujeto en su producción como testigo y personaje; si, en fin, el trauma deviene efecto a posteriori de una tensión que es "universal" (la naturaleza pulsional) y contingente a la vez (el recorrido histórico de los avatares de la sexualidad en la introducción del Otro en su constitución subjetiva); todo ello corre a la par de un movimiento de escritura por el cual es la propia teoría, el propio Freud como autor el lugar temporal donde deviene acto de enunciación.

Ahora bien, si respecto a Charcot, estas diferencias permiten situar la "novedad" freudiana en relación al estatuto metodológico de sus apuestas clínicas, y con ello operando como en tensión frente a ese tiempo donde la ciencia médica podía hacer ingresar lo aborrecible o lo enigmático de la vida cotidiana en las figuras de La Enfermedad, a partir de una subjetivación creciente del síntoma en la alteridad de lo que se llamará transferencia, es posible también reconocer en los contenidos mismos de sus apuestas teóricas -particularmente acerca de la naturaleza del síntoma histérico- una perspectiva igualmente heterogénea.

Así, otra lectura mediante la cual el trabajo freudiano muestra su heterogeneidad respecto al espíritu psicopatológico de su época, se refiere ya no a la relación con uno de sus maestros, sino a un contemporáneo cronológicamente, pero que podemos consi- derar para nuestros fines como un exponente de la lógica que Freud dejó, al menos en parte, atrás. Se trata de Pierre Janet. Aquí las diferencias son mas explícitas, dado que la posición del maestro no opera ya. Si la crítica de Freud a Janet suponían que en las duplicidades de la conciencia o de la organización de la personalidad el elemento sexual aparecía descuidado y, en un sentido más extendido, implicaban un concepto de aparato psíquico que no reconocía una realidad "otra" que los fenómenos de la conciencia aún como sub-consciencia-, la crítica de Janet a Freud descansaba precisamente en esa aparente obsesión por llevar los fenómenos histéricos a la causa "única" de la sexualidad.

Así, por ejemplo, la histeria para Janet es una enfermedad causada por representaciones pero, sobre todo, donde se han debilitado las capacidades unificadoras (de "sintesis") de su Yo. Se trata de la clásica evocación de la Unidad y de las Funciones, donde el recorrido "de Pinel a Freud", se había encaminado para tramitar -expurgando- la tragedia y el conflicto de un "nuevo" sujeto. Esto adquirirá formulación explícita cuando la neurosis (la histeria) sea entendida como un trastorno de personalidad. Esta noción, que será clave para entender algo de nuestras actuales figuras limítrofes, precisamente en la medida que éstas subrayan mas o menos los mismos criterios de Janet acerca de la histeria, supone : a) que el sujeto es un individuo, b) cuya vida psíquica está organizada por un conjunto de representaciones que tiene a la conciencia como su expresión fenoménica más precisa y d) que se estructura mediante un sistema definido como una entidad (el Yo) compleja.

Ahora bien, no es muy difícil señalar cómo Freud cuestiona punto por punto estos supuestos.

a) el sujeto no es un individuo (solamente). Es de hecho en el límite de su unidad (conciente o no) donde su poder (de "síntesis") se muestra como deter- 
minado por un tipo de realidad cualitativamente diferente a la conciencia o a la organización yoica.

b) La vida psíquica no está constituida solamente por representaciones, ni siquiera por representaciones $y$ afectos, sino por la tensión (por la exigencia de trabajo) que lo corporal (o en cierto modo lo afectivo) le impone a lo psíquico (vertiente pulsional), pero donde lo psíquico (lo representacional, en el sentido de Janet) le otorga a la pulsión una vía de tramitación subjetiva.

c) La conciencia no es el criterio central de lo psíquico, ni siquiera cuando se incorpore lo "sub-conciente" como noción "psicodinámica" y menos aún con los correlatos psicofisiológicos de un estado de tensión psíquica sobre la cual operaría la formación de síntomas;

d) Y, sobre todo, "el yo no es amo en su propia casa".

El parentesco entonces de las hipótesis de Janet acerca de la histeria en relación al ("primer") Freud es solo aparente o parcial. Porque si bien podía reconocer-y subrayar-cuánto había de historia en la actualidad del síntoma o del "accidente" histérico, subrayando que la aparente versatilidad de las apariencias sintomáticas escondía una cierta estabilidad "repetitiva", al mismo tiempo el viejo recurso a la constitución, a las "debilidades", no permitía introducir un concepto "dinámico" por el cual esa ligazón a acontecimientos anteriores, esa quieta movilidad de los síntomas, introdujera el conflicto como parte integrante de su "funcionamiento", y más bien permanecía en el clásico recurso a las "tendencias" (al "desdoblamiento de la personalidad"). Freud opone entonces a esta visión "constitucional" una vía "dinámica" para subrayar el estatuto conflictivo del síntoma y del sujeto: “mientras que la psiquiatría para dar cuenta de las pulsiones extrañas al yo dice 'degenerescencia, disposición hereditaria, inferioridad constitucional', el psicoanálisis dice fuerzas internas y conflictivas, de las cuales el paciente debe asumir su responsabilidad" (Freud 1990르, p. 184-185).

Una concepción "dinámica" que introduce el elemento sexual (descuidado por Janet) como necesario a esa conflictiva y que llenará de "contenido" el estatuto traumático del síntoma. Más tarde, lo sexual en cuestión permanecerá "indefinida" o "repetitivamente" al interior de la teoría, aun cuando sus contenidos de "realidad" vayan superando las metáforas biológicas o, incluso, los datos de la experiencia. Habrá algo traumático en la realidad misma ... para un sujeto. Por otra parte, será en la elaboración de la segunda tópica donde se podrán sancionar más o menos definitivamente las antiguas alianzas de formación freudianas: así, el esfuerzo metapsicológico comandado por una necesidad de construir una representación a la vez tópica, económica y dinámica del aparato psíquico, será el terreno donde las apuestas "descriptivas" que sostenían sus antecedentes "filosóficos" (es así como Freud remite al concepto descriptivo de inconsciente que su elaboración metapsicológica desmontará teóricamente) den paso a una "ficción" teórica que haga del descubrimiento del inconsciente un asunto de sujeto.

Todo esto para decir que Freud no es sólo el heredero o la continuación de esa vieja historia donde la razón, luego la ciencia, aquí la psiquiatría, se habrían encaminado a disolver la verdad trágica del sujeto, mediante su definición como objeto y mediante la fijación "sintética" de su vocación unificadora. La intervención freudiana en el seno de esa cultura, ocurre a expensas del saber psiquiátri$\mathrm{co}$, pero para disolver sus promesas en otra 
versión de la tragedia que aquél había olvidado como un mal recuerdo. $Y$ lo ha hecho no sólo al interior de la lógica clínica misma; aquélla que hacía del síntoma un texto, el sufrimiento una experiencia del sujeto en su división y en sus conflictos, y donde la implicación de su propia subjetividad se hacía parte de lo que podía reconocer en la palabra de sus pacientes-incluso a costa de sus fracasos.

Ahora bien, los dos aspectos que hemos introducido como antecedentes para una lectura "actual" de la clínica psicoanalítica, entendida como una de las maneras de nombrar el lazo social que la define, esto es, la relación psiquiatría/psicoanálisis en Freud, por un lado, y la historicidad del "síntoma psicoanalítico", por otro, nos permiten sentar las bases para analizar en específico una de las maneras como tales antecedentes se expresan contemporáneamente.

En efecto, se trata ahora de poner en juego ese marco teórico/histórico para abordar - a la manera de un "síntoma" - el problema de la relevancia actual de la clínica psicoanalítica, a la luz de sus impases contemporáneos. Aquí donde la relación psiquiatría-psicoanálisis opera como un nuevo conflicto y donde la relación de la doctrina psicoanalítica a la historia revela sus compromisos actuales. Por ello, nos interesa discutir, a la manera de un ejemplo preciso, cómo operan las hipótesis sugeridas precedentemente.

\section{Análisis: Los "Trastornos}

\section{Limitrofes de la Personalidad" y la Clínica Psicoanalítica Actual}

El problema de los llamados "trastornos limítrofes de la Personalidad" (Kernberg, 1993) nos ofrece un material específico donde se manifiestan los impases y las posibilidades de una clínica de "lo actual". Ello considerando tanto los aportes que dicha noción puede representar para analizar la historicidad de las categorías nosológicas (a la par que la historicidad del sujeto que las sostiene), como una necesaria evaluación de lo que ellas pueden tener de recurso sintomático, es decir, que describen dicha historicidad, pero a costa del préstamo de otro tiempo: precisamente aquel que marcó la diferencia de Freud respecto a la clínica de su época. El problema que se plantea aquí es saber si tales construcciones son efectivamente "actuales" o si no hacen más que reverberar en las antiguas definiciones que marcaron la antesala del freudismo de principios del siglo XX. Nos parece que en torno a este problema se juega la cuestión de la historicidad del psicoanálisis en función de sus compromisos institucionales -incluso ideológicos- cuando es leída en virtud de su lugar en la ciudad. Compromisos que, en este caso, se expresan en la relación psiquiatría / psicoanálisis.

\subsection{Una vieja historia}

El tema de los "borderlines" en la nosología psicoanalítica, ha implicado un intento por reformular los criterios por los cuales la clínica freudiana estableció la ya clásica distinción de neurosis/psicosis, a la luz de los desafíos que presenta el estatuto actual del síntoma, así como las consecuencias que tiene su presencia contemporánea en las llamadas "nuevas enfermedades del alma" (Kristeva 1993). Los trastornos limítrofes de la personalidad, o los estados-limites si utilizamos la nomenclatura francesa (Bergeret 1996), evidencian parte importante de los impases a los cuales se enfrentan los clínicos de hoy, cuando tienen que vérselas con las provocaciones transferenciales, las resistencias al tratamiento y las dificultades que estos pacientes presentan al trabajo asociativo y a su propia historia de relaciones. La tendencia al "acting", las dificultades para ser ubicados en las categorías 
nosográficas tradicionales, y los no menos difíciles rasgos de su carácter (por ejemplo, "la dificultad de enamorarse")(Kernberg 1995), parecen indicar tanto un obstáculo para el tratamiento y la nosología psicoanalítica, como una posibilidad que sitúe a la clínica en su relación a los desafíos que presenta una experiencia, siempre móvil (Stryckman 1996).

En este sentido, la clínica de los "límites" constituye un territorio privilegiado para analizar la posición del psicoanálisis en sus desafíos contemporáneos, para lo cual ha debido asociarse más o menos directamente a la clínica psiquiátrica -sobre todo en el medio hospitalario. Tales desafíos acarrean preguntas que atañen no solamente a discusiones técnicas (setting, diagnóstico, posibilidades interpretativas, etc.), sino que se dirigen a problematizar nuevamente el rol del clínico (psiquiatra, psicoanalista o psicólogo) frente a las exigencias que le plantea la realidad de su experiencia, a la luz de la realidad del contexto socio-cultural donde ésta opera. Se puede pensar que la discusión sobre el estatuto actual del síntoma, cuando es pensada a partir de las condiciones culturales del sujeto de hoy, encuentra en el problema de los "límites" un lugar donde formularse críticamente.

Ahora bien, un análisis detenido de esta noción, que tiene por lo demás una historia que cruza parte importante de los desarrollos postfreudianos (Kouretas 1996), evidencia un hecho indesmentible: la mayoría de los rasgos que le son atribuidos a este tipo de pacientes, incluso las dinámicas psíquicas que le serían propias, no esperaron nuestro tiempo para ser formulados, y si podemos ser más radicales aún, no esperaron a Freud para plantearse como novedades de la estructuración subjetiva. En este sentido, es posible rastrear toda una genealogía conceptual que parte desde las primeras intuiciones de Pinel, a principios del siglo XIX, que se prolonga en la nosología del alienismo francés (Esquirol), que se continúa en las apuestas relativas a las psicosis-histéricas (Bercherie 1983), incluso en las perversiones cercanas a los alrededores freudianos, y que acaba por formularse en ese territorio híbrido que las nomenclaturas de la psiquiatría de principios del siglo XIX definieron a partir de una perspectiva "psicodinámica". Es posible encontrar en las exigencias a la clasificación, en las provocaciones histéricas, en las atribuciones caracterológicas -o incluso "morales"- de la psiquiatría del siglo XIX y de parte importante del XX, toda una prehistoria de las categorias por las cuales son definidas nuestras actuales limitaciones diagnósticas.

La pregunta que surge entonces es: ¿a qué obedece esta aparente novedad de los "límites" de hoy, cuando parecen tener toda una historia?¿A qué responde la necesidad de incorporar los "aportes de la ciencia" actual (cognitivismo, neurociencia, teorias de sistemas,etc.) en las estrategias nosológicas y nosográficas actuales para definir estas nuevas patologias del espíritu? Finalmente, ¿qué consecuencias implican estas aparentes novedades si las leemos en función del lugar institucional de los compromisos políticos y culturales del psicoanálisis en este tiempo?

\subsection{Sobre las decadencias del espiritu}

En el intento de desplegar algunas hipótesis que nos permitan avanzar en la discusión de estas preguntas, es posible plantear, tal vez polémicamente, las siguientes proposiciones:

3.2.1. La recurrente necesidad por reformular las categorías nosológicas y nosográficas en psicoanálisis y psiquiatría, forma parte de su propia naturaleza discursiva y de sus propios compromisos históricos. Esta discursividad implica, directa o 
indirectamente, lo que llamaremos una cierta nostalgia. Cada vez que la sociedad o la cultura en la cual estos discursos operan se halla sometida a la necesidad de fundar sus referencias identitarias (tales como la revolución cientifico-teconológicas del siglo XIX o la revolución informática del siglo XX), estos mismos discursos se encargan de tramitar dichas referencias mediante la inveterada apelación a una "decadencia". Sea que ésta tome la forma de un ocaso de las representaciones, de un fin del relato, de una apocalíptica enunciación del "fin de la historia", o que se exprese apelando a la decadencia de las antiguas referencias familiares o "simbólicas" (la familia, el padre, la religión, el encantamiento del mundo), lo cierto es que una constante de los discursos disciplinarios, incluidos aquí el discurso psiquiátrico y psicoanalítico, supone apelar a un tiempo anterior para fundar una cierta "novedad".

Sin embargo, es posible reconocer que mediante estas aparentes actualizaciones opera una paradoja central para analizar el lugar de tales discursos en el marco de la historicidad del sujeto en la cultura. Porque a través de ellas no sólo se niega lo que efectivamente puede haber de actual en las vicisitudes de la clínica, sino que se propone una novedad que es parte de aquello que precisamente se quiere superar o relativizar histórica y teóricamente. En este contexto, las formulaciones relativas a los "bordes" en la clínica de hoy sirven como un ejemplo especialmente ilustrativo. Por una parte, debido a que podemos encontrar en los enunciados que las representan, toda una referencia implícita a otras escrituras del síntoma, precisamente aquellas que formaron parte del tiempo que se quisiera reconocer como "otro". Es el caso, a modo de ejemplo, de las apelaciones a lo no-analizables de ciertos pacientes; sea que se planteen hoy dia asociadas a la decadencia de la palabra y a la pobreza de los vínculos, sea que anteriormente se plantearan como obstáculos que ciertos pacientes ofrecían a los clínicos en sus engaños transferenciales. Es el caso también de las referencias cognitivas para definir lo que antes se presentaba en el teatro privado de las histerias (Janet, Charcot, Freud) y que hoy día se propone como un salto epistemológico hacia la construcción de las realidades y a la definición de las identidades. Es el caso, también, de las apelaciones morales a los "límites" de hoy, que recapitulan en parte importante la higiene de otras "debilidades" psíquicas o sociales. Finalmente -aunque la lista podría seguires el caso de las apelaciones a la "personalidad", ahí donde la clínica de Janet o de Charcot quisieron formular el escenario de las conciencias en la clínica de las neurosis, y que hoy en día se plantea a propósito de las unificaciones más o menos (es generalmente el caso) logradas de las alternancias de la representación de si mismo, en las "nuevas" tecnologías del Yo.

3.2.2. La existencia de estas "nuevas patologias" hay que leerla a partir de ciertos compromisos institucionales por parte de los agentes que las formulan teóricamente y que proponen tramitarlas en el espacio cada vez más amplio de ls clínica psicológica -o psiquiátrica. En este sentido, el matrimonio psiquiatría-psicoanálisis, cuya historia bosquejamos críticamente en nuestra primera sección de este trabajo, vuelve a aparecer en escena para dar cuenta de las aparentes novedades de la clínica actual. En este caso, la especificidad crítica del psicoanálisis freudiano, como el de algunos de sus desarrollos posteriores, tiende a perderse en la galería de recursos tecnológicos que permiten, paradójicamente, que el discurso normalizador de la clínica decimonónica adquiera una nueva versión, con lo cual la influencia de estas nuevas nomenclaturas no hace sino profundizar las estrategias disciplinarias 
(por ejemplo, la clasificación psiquiátrica o la teconologia farmacológica) (Lanteri-Laura 1984; Zarifian1986, 1994) que sirvieron de antesala o de reverso al psicoanálisis en Freud para tramitarse críticamente de otro modo (en Freud mismo). Desde este punto de vista, no parece casual que una nueva higiene científico-psicológico-moral venga a relevar los antiguos dispositivos por los cuales la enfermedad mental adquirió cartas de ciudadanía, pero para habilitar otros excesos de poder. Paradójicamente, hemos dicho, los ecos de esa vieja práctica segregativa que constituyó el nacimiento y despliegue de la psiquiatría decimonónica alcanzan -esta vez mediante los más sutiles ejercicios de la medicalización- nuevos efectos, de los cuales la renuncia a pensar teóricamente los aportes más críticos de Freud no es sino una de sus versiones.

3.2.3. En resumen, hoy más que nunca es necesario tomar en serio la necesidad de la historia, tanto para reconocer en qué medida los dispositivos disciplinarios actuales no hacen sino recapitular otra época -sin saberlo-, como para enfrentar creativamente la historicidad del sujeto en lo que tiene de verdaderamente actual. Para ello, sin ser más que una de las posibilidades críticas en el dominio de la clínica contemporánea, la originalidad del psicoanálisis en nuestra época -y su eventual "decadencia"- debe analizarse a partir de lo que ofrece como posibilidad crítica de la historia del presente.

\section{Discusión}

\section{Clínica y escritura o el psicoanalisis en la cultura}

Hemos discutido en los antecedentes teórico-históricos de este trabajo la manera como una discusión sobre la historicidad de la clí- nica psicológica -o psiquiátrica- es correlativa a una discusión sobre el sujeto en la cultura y a la función que desempeñan ahí las diferentes versiones de la disciplina psiquiátrica y/o psicoanalítica. Hemos señalado que este tema concierne a la relación psiquiatría/ psicoanálisis en cuanto a las condiciones de su aparición como discursos. Por otra parte, hemos indicado el sentido de una reflexión histórica acerca de esta discursividad diversa, apuntando a reconocer en la obra freudiana un intento por hacer suyas las dimensiones subjetivo-culturales de la época que la vio nacer, pero para formularlas de otro modo. Hemos dicho, finalmente, que la radicalidad de la crítica freudiana, así como los conceptos que le son propios -y que permiten mostrar ya en su época sus diferencias con respecto a la racionalidad psicopatológica de la medicina de lo mentalapunta precisamente a deconstruir la lógica por la cual los problemas clínicos han sido formulados clásicamente, y que alcanzan en nuestro tiempo una renovada $-y$ negadaactualidad.

Nos interesa, para concluir, avanzar en una discusión que, apoyándose en las hipótesis precedentes, permita aportar al debate sobre la clínica psicoanalítica entendida en función del lazo social del que forma parte inevitablemente.

\subsection{Etica versus epistemología}

Pensar los aportes que ofrece el discurso psicoanalítico para discutir la historicidad del sujeto, compromete la lectura que podemos hacer, a posteriori, de la revolución freudiana. Ello debido a que, como toda praxis humana, el psicoanálisis representa en sus propios compromisos discursivos -es decir, tanto teóricos como clínicos- el lado disciplinario de lo que el sujeto -o el paciente- se encarga de mostrar y de padecer con su sufrimiento y su alienación. Discutir el lugar "actual" del 
síntoma o de las "nuevas" formas de subjetividad, es de hecho análogo a discutir lo que el saber que la nombra (en este caso, psiquiatría y/o psicoanálisis) tiene de ese mismo sufrimiento y de esa misma alienación histórica. Es por eso que hablamos de discursos, porque este concepto compromete tanto al saber como a los "objetos" que pretende ilusoriamente administrar como ajenos a él.

En este contexto, es necesario superar una tentación contemporánea, que propone discutir el lugar de las disciplinas en la cultura, a través de sus compromisos epistemológicos. El problema del lazo social que la clínica psicoanalítica establece con respecto a la subjetividad actual, es menos pensable en función de los "mapas" epistemológicos que puede oponer a otras formas de entender la psicopatología -o al sujeto mismo- (por ejemplo, en virtud de las diferencias con una clínica de la experiencia o una clínica de las representaciones), que en función de la manera como las apuestas clínicas y teóricas tramitan sus propios límites, sus propios enigmas, en el ejercicio de sus intervenciones, de sus saberes y de sus poderes. En este sentido, es pensable que las virtudes de la clínica freudiana se basan precisamente en el reconocimiento de sus propias limitaciones, de su propio no-saber, pero sin descuidar el ejercicio teórico que es el resorte de su audacia y de su crítica. Tal como lo diría Jacques Lacan, la cuestión del inconsciente no tiene nada de pre-conceptual, es decir de estructurado como discurso y teniendo como fundamento el lenguaje que lo determina humanamente; y sin embargo ese carácter estructurado del "inconsciente como lenguaje" no impide que éste sea considerado como lo que se pone an acto en la singularidad de la historia de cada cual y en la manera como dicha singularidad se desdobla en el análisis de la transferencia.

Lo anterior implica, para nuestros propósitos, que el problema de la originalidad -si es que es tal- de la invención psicoanalítica, no reside en ser una teoría abstracta sobre el sujeto sobre el cual opera conceptualmente; es mucho menos una teoría orientada epistemológicamente, que una práctica definida por los compromisos siempre "éticos" del sujeto-analista y del sujeto-paciente. Cuestión, por lo demás, que acarrea consecuencias para el concepto de inconsciente mismo, definido entonces como "ético" en su propia estructura de discurso.

Decir entonces que el problema del psicoanálisis como clínica en el lazo social, implica una ética, supone plantear que su valor como apuesta crítica del sujeto moderno releva de la manera como el clínico (psicoanalista) se hace parte de la alienación que lo constituye tanto a él como a "su" analizante. Toda la cuestión de la ética analítica reside en que se trata de una alienación que debe ser analizada. Es decir, si la clínica psicoanalítica nos dice algo de la alienación del sujeto actual, es mucho menos debido a que ofrezca un marco intepretativo de las dependencias del sujeto a un discurso que lo antecede, que una praxis por la cual tanto uno como otro (el psicoanalista y el paciente) desdoblan sus dependencias para intentar ir más allá de ellas. Si bien no existe garantía de que tal proceso se lleve a cabo, al menos es pensable que las condiciones que lo permitirían tienen aquí (con el psicoanálisis) una posibilidad de experimentarse clínicamente (y críticamente).

\subsection{Hacia una desmedicalización del aná- lisis}

Pensadas así las cosas, es la ubicación misma del psicoanálisis en los saberes y prácticas de nuestro tiempo la que debe ser analizada recurrentemente. Lejos de pensarla como siendo parte de la medicina (o de la psiquiatría), es necesario considerarla en el marco de una teoría crítica sobre el sujeto en 
su alienación y en su sufrimiento. Por ello, un desafío que se le plantea al psicoanálisis (a los psicoanalistas más bien) es pensar su "identidad" más allá de las fronteras institucionales a las cuales generalmente se le asocia. Es sólo en el diálogo con otras disciplinas, incluido ahí el discurso médico también, que el psicoanálisis puede pensarse como otra cosa (otra escena, decía Freud a propósito del inconsciente) y que no descuide sin embargo su dependencia a esos mismos saberes de los que podría desprenderse en parte.

Esta cuestión institucional, incluso política del lugar del psicoanálisis en nuestra cultura, es particularmente relevante cuando las sirenas de una cientificidad ciega, de una tecnología miope, llaman a descuidar el trabajo teórico para proponer en cambio una nueva lógica de la adaptación, en el marco de nuestras nuevas o renovadas Tecnologias del Yo, por utilizar la expresión de Michel Foucault.

\subsection{La escritura y el tiempo}

El trabajo freudiano es un trabajo en el tiempo y con el tiempo. Su escritura releva de un ejercicio de pensamiento que no niega las referencias (simbólicas, identitarias, culturales, etc.), pero que las traduce en la experiencia singular y social del sujeto enfrentado a sus determinaciones, para decirlas de otro modo y tal vez poder cuestionarlas creativamente. Decimos que se trata de una escritura en tanto práctica de lenguaje en la historia.

Es en este contexto que las actuales discusiones sobre el "paciente de hoy" o, más extensamente, "la subjetividad contemporánea", merecen ser examinadas como prácticas actuales, pero que recorren sin saberse del todo la genealogía de otros discursos y de otras culturas. El sujeto llamado "actual" no es solamente el triste efecto de una nueva tragedia, es también el lugar donde los destinos de la palabra y de las acciones pueden formularse críticamente en tanto prácticas de escritura. De ahí, finalmente, que el famoso problema de las "decadencias" en nuestra cultura, deben ser pensadas en lo que anuncian de nuevos desafíos para la psicología, el psicoanálisis, la psiquiatría o las ciencias sociales, pero también como síntomas de una época que se niega a ser otra. No es esto otra cosa que aquello que nuestras subjetividades expresan con su desconsuelo, pero también con su esperanza. Aquí donde el trabajo de autor -mucho más que de autoritarismopermita avanzar en una perspectiva crítica que hable realmente de otro tiempo.

\section{Conclusiones}

La teoría y la práctica del psicoanálisis puede leerse como síntoma cultural. Ella interroga, en su quehacer mismo, los límites y las posibilidades de una psicología (o de una experiencia de pensamiento en general) cuando se enfrenta a las exigencias de su ubicación en la cultura. Son sus contradicciones internas, su doble dependencia/rechazo al saber médico, del cual recibe su carta de nacimiento, los aspectos que hacen de esta experiencia un asunto conflictivo. Conflictivo no solamente en función de los saberes más validados "científicamente" en el seno de la modernidad, sino al interior de su propio territorio enunciativo.

En tanto práctica en la cultura, el psicoanálisis debe entenderse en su dimensión social, histórica e incluso institucional. Y es en la crítica que habilita, incluso en el rechazo más radical del que es objetio, por donde ilumina algo de los desafíos de la época actual. Lejos de constituirse como una perspectiva clínica más, el psicoanálisis se nos presenta en su dimensión antropológica en tanto pone 
en juego las exigencias que a la subjetividad le plantean los discursos y las modalidades sociales del intercambio humano. E intenta -sin que nada asegure que lo logre- insistir en el carácter fundamentalmente conflictivo -trágico, diremos- de la experiencia subjetiva y social. Los conceptos que son producidos en este contexto, la utilidad o la ineficacia de su práctica, deben leerse en función de estos límites, que son también la posibilidad de una apertura de sentido.

De ahí que la ubicación epistemológica, ética, institucional e incluso política del psicoanálisis, representan un dominio de reflexión a partir del cual la posibilidad del sujeto-su insistencia misma- puede ser interrogada como asunto de cultura y de experiencia. Pero para ello es necesario someter al propio psicoanálisis a la crítica que, explícita o implícitamente, habilita como producción de pensamiento y de lenguaje. Sólo entonces, en esa necesaria reflexión-histórica, teórica, técnica- acerca de sus compromisos y de sus cegueras, el psicoanálisis puede decirnos algo de lo que somos o de lo que ignoramos ser.

\section{Referencias Bibliográficas ${ }^{3}$}

Aceituno, R.(1999). Proposiciones sobre la clínica como discurso 'actual'. Revista de Psiquiatría, 6; 215-220.

Aceituno,R. y Rosas,M. (Comp.)(1999). Psicoanálisis: sujeto, discurso, cultura. Santiago: Ed. Universidad Diego Portales.

Andersson, O. (1997). Freud avant Freud. La préhistoire de la psychanalyse. Paris: Ed. Synthélabo.

Assoun, P.L.(1990). "Le récit freudien du symptôme". Nouvelle Revue de Psychanalyse, 4 ; 176-177.
Assoun, P.L. (1995). L'imaginaire métpasychologique. Théorie et fantasme chez Freud, En: Texte, p. 219 y ss.

Bercherie, Paul (1988). Géographie du champ psychanalytique, Paris: Navarin.

Bercherie, Paul (1983). Le concept de folie hystérique avant Charcot Rev.Int.Hist.Psychiatr.,1; 207-228.

BERGERET, J. (1996). L'incertaine subtitilité des limites nosologiques. Une écoute psychanalytique de la psychopathologie de l'adulte. Reoue Française de Psychanalyse. 2; 299-316.

BIRMAN,J. (1999). Psicoanálisis y nuevas formas de malestar en la civilización. ¿Tiene porvenir el psicoanálisis?. En: R. Aceituno \& M.Rosas (Eds.): Psicoanálisis: sujeto, discurso, cultura (107-122). Santiago de Chile: Ed. Universidad Diego Portales. (Orig.1996)

Castel, R. (1976). L'ordre psychiatrique. Paris: Minuit.

Certeau, M. (1986). Histoire et psychanalyse, entre science et fiction, Paris:Gallimard.

Charcot, J.M., (1888). Lecons du mardi à la Salpêtrière. Policlinique 1887-1888. Notes de cours de MM. Blin, Charcot, Colin. Paris: Progrès médical /Delahaye \& Lecrosmier.

ChILANd, C. (1990). Homopsychanalyticus, Paris: PUF.

Decourt, P. (1996). Entre clivage et confusion. Revue Française de Psychanalyse, 2;381-397.

Didi-Huberman, G. (1994). L'invention de l'hystérie: Charcot et l'iconographie de la Salpêtrière. Paris: Macula.

Foucault, M. (1996). Histoire de la folie à l'age classique. Paris: Gallimard. (Orig. 1972).

3 Dado el origen de este texto, las referencias utilizadas corresponden en su mayoría a la traducción francesa de las Obras de S. Freud. Se señala una traducción libre de tales títulos para facilitar la lectura. Las citas son traducidas al español por el autor. 
Foucault, M. (1996). Il faut défendre la societé, Cours au Collège de France. Paris: Hautes Etudes/Gallimard/Seuil.

Foucault, M. (1997). Naissance de la clinique. Paris: PUF. (Orig. 1963).

Freud, S.(1990). Conferencias de introducción al psicoanálisis, 16 a Conferencia: Psiquiatria y Psicoanálisis.En: Obras Completas, Vol. 16, Buenos Aires: Amorrortu.(Orig. 1917).

Freud, S. (1990b).Une difficulté en psychanalyse", en: L'inquiétante étrangeté et autres essais, Paris: Gallimard.(Orig. )

Freud, S. (1984). L'interêt de la psychanalyse, En: Résultats, idées, problèmes, Vol. 1, Paris: PUF.(Orig.1913).

Freud, S. (1984b). Psychanalyse et théorie de la libido, En: Résultats, idées, problèmes (69-70). Paris: PUF.

FREUD, S. (1974). Nouvelles remarques sur les psychonévroses de défense, En: Névrose, Psychose, Perversion, Paris:PUF.(Orig.1896).

Freud, S. (1990c). L'établissement des faits par voie diagnostique et la psychanalyse. En: L'inquiétante étrangeté et autres essais. Paris:Gallimard. (Orig.1906).

Freud, S. (1981). Au-delà du principe de plaisir, En: Essais de psychanalyse, Paris: Payot.(Orig.1920).

Freud, S.(1986). L'homme Moise et la religion monotheiste.

Paris:Gallimard.(Orig.1939).

FREUD, S. (1990d). La interpretación de los sueños. En: Obras Completas, Vol. 4. Buenos Aires: Amorrortu editores. (Orig. 1900).

FReUd, S. (1973): Le trouble psyhcogène de la vision dans la conception psychanalytique, En: Nèvrose, psychose et perversion, Paris: PUF. (Orig.1910).

GaLe, N. (ed.)(1978). L'introduction de la psychanalyse aux Etats-Unis. Paris: Gallimard.

GAUCHET, M. (1984). À la recherche d'une autre histoire de la folie, En: Swain, G. \&
Gauchet, M., Dialogue avec l'insensé (22-23), Paris:Gallimard.

Janet,P. (1894). L'état mental des hystériques, Paris: Alcan.

Kernberg, O. (1993). Desórdenes fronterizos y narcisismo patológico. México: Paidos.

KernBerg, O. (1995). Relaciones amorosas. Normalidad y patología. Buenos Aires: Paidos.

Kouretas, N.(1996).Le développement $d u$ concept de borderline (état-limite) dans le diagnostic et le traitement psychanalytique. En: M.Tort et al : Lacan et la psychanalyse américaine (29-34). Paris: Denoël.

KRISTEVA, J. (1993). Les nouvelles maladies de l'âme. Paris: Fayard.

Laplanche, J. E \& Pontalis, J.B.(1985). Fantasme originaire, fantasme des origines, origines $d u$ fantasme, Paris: Hachette.

Lanteri-Laura, G. (1984). Classification et semiologie. Confrontations psychiatriques, $24 ; 58$ y ss.

Le GUEN et al (1989). La psychanalyse: une science?, Paris: Les Belles Lettres.

MenaHem, R.: (1996). Aux origines d'une mésaillance. Psychanalyse et psychiatrie. Revue Française de Psychanalyse, 2; 561-569.

Narot, F. (1990). Pour une psychopathologie historique. Introduction à une enquete sur les patients d'aujourd'hui. Le Debat, 61; 165-186.

Porge, E. (1984). La présentation de malades: Charcot, Freud, Lacan, aujourd'hui", En : Un siècle de Recherches freudiennes, Paris: Eres.

StRYCKMAN, N. (1996). Les états-limites: une commodité psychiatrique et un embarras psychanalytique?. Le Bulletin Freudien, 28; 4957.

Swain, G \& Gauchet, M..(1997). Le vrai Charcot. Les chemins imprévus de l'inconscient. Paris: Calman-Lévy. 
Trillat, E. (1986). Histoire de l'hystérie, Zarifian, E. (1986). Un diagnostic en Paris: Seghers.

WeBER, M.(1964). L'ethique protestante et l'esprit du capitalisme, Paris:Payot. psychiatrie: pour quoi faire?, en (Colectivo): La querelle des diagnostics (84-86). Paris: Navarin.

ZARIFIAN, E. (1994). Des paradis en plein la tête. Paris: Odile Jacob. 